\title{
Ultra-High Pressure Chilled Meat Processing: A Promising Storage Method
}

\author{
Sergei Tikhonov, Natalya Tikhonova, Vladimir Lazarev, Elena Samokhvalova, Leonid \\ Minukhin, and Gennadiy Pischikov
}

Ural State University of Economics, 620144 Ekaterinburg, Russia

\begin{abstract}
The positive effect of ultra-high pressure on the shelf life of chilled meat during refrigerated storage has been established. It has been proven that 6 minutes meat processing at the $800 \mathrm{MPa}$ pressure provides high organoleptic characteristics (color, smell, texture), microbiological safety, so KMAFAnM, yeast and other studied parameters do not exceed the requirements of the technical regulation of the Customs Union "On Food Safety" (TR TS 021/2011), prevents the breakdown of protein and does not result into oxidative damage. At that time, samples of chilled meat not processed by pressure, after 60 days of refrigerated storage, corresponded to stale meat according to organoleptic, physiochemical and microbiological indicators. Therefore, the processing of meat, packed in vacuum packaging, helps to increase its storage time. We have calculated the design of equipment for processing meat with high pressure, by comprehensive compression of the working fluid in a special working chamber.
\end{abstract}

\section{Introduction}

One of the promising technologies for storing perishable food products is its processing with ultra-high pressure up to $1000 \mathrm{MPa}$, which is due to the ability to inactivate microorganisms by pressure, to preserve the initial properties of the product: color, smell, taste, structure and nutritional value $[1,2,3]$. High pressure food processing is used in European countries and the USA [4,5]. Moreover, thanks to pressure treatment it is used in the processes of rapid freezing and thawing of products. In this case, the ice crystals formed are very small and do not damage the cellular structures of the biomass.

Food products processing allows you to get products with high functionality, while maintaining the original nutritional value. In the literature there are conflicting and even a priori data on the effect of high pressure on the structural and functional properties of condensed globular proteins [6,7], technological modes of processing food protein systems, including globular proteins [8.9], and protein compositions [10.11]. But at the same time, the process of food pressure processing has not been studied enough, the equipment used is expensive, and there is a difficulty in all production processes automation when integrating ultra-high pressure equipment into an automatic technological process $[12,13,14]$.

The current state and prospects of new food production branches make it possible, even at the present level of agricultural development, to sharply increase food resources and, most importantly, increase its quality, as well as the economic indicators of the 
corresponding industries. A large role in the development of processes for obtaining new food products and their conservation is given to the system for the development of new food technologies, such as technologies using high pressure. At the present stage of food production development, the role of food raw materials quality, due to the methods of its storage and processing, is significantly increasing. Therefore, there is a need to develop a qualitative new way of food products preserving, which consists of the high pressure application. The main objective of this technology is to get high quality food with long shelf life. This new food storage technology should be practically applied and correspond to the intensification goals, as well as to the food safety improving. Food products obtained from raw materials of plant and animal origin as a result of its processing with high pressure are usually called new forms of food in the scientific literature. This food is intended to replace a significant portion of traditional food products that are produced using thermal methods. The permissible level of replacement is determined by the effectiveness of this processing method and the functional properties of the resulting product. Food technologies using high pressure are undoubtedly convenient for customers: high-pressure sterilized staple foods such as cheese, meat, fish and and other products retain color, smell and texture; vegetables and fruits fully retain their structure; soups, sauces, stews have neither boiled smack, nor disturbances in the structure, as it is observed in products that have undergone heat treatment, or freezing. The industrial introduction of products preservation new technology based on high pressure application has been quickly developed in the last decade in almost all developed countries $[15,16]$.

According to their type, ultra-high pressure food processing technologies are usually divided into two large groups - batch and continuous ones.

Any ultra-high pressure device consists of a high-pressure tank (chamber) and a powerful pump; it can also have a device for heating or cooling [17].

In economic terms, food products (usually juices) high pressure continuous processing systems are most attractive. Liquid products occupy $100 \%$ of the working chamber volume, while the maximum filling with packaged products is only $75-80 \%$. The energy spent is $1 / 10$ of what is required for pasteurization of the juice. With pressure increasing, the amount of energy expended and the duration of the process increase. The optimal (in terms of energy costs) pressure is $350-400 \mathrm{MPa}$. The use of higher pressure leads to a sharp increase in energy costs. Soon, high-pressure food processing plants with 25 liter working chambers for compression of juices with low $\mathrm{pH}$ will be created. According to foreign experts, financial costs per 1 liter of products will be $5-8$ cents. The near future technology improvement is expected to reduce these costs up to 1-4 cents [18]. Currently, the industry does not yet have facilities for processing high-pressure food products of this type. A continuously working system should compress the liquid food product, taking into consideration that the flow is stopped either in the outgoing communications or in the working chamber itself to comply with the required holding time. In addition, some time is to be spent on decompression of the liquid product to prevent it from boiling, sudden thermal changes in the outlet pipe, which leads to the equipment depreciation. The decompressed and processed liquid is led into a sterile tank for subsequent packaging. An experimental setup for continuous high-pressure treatment of yogurt with its simultaneous homogenization was described in the article [18]. Liquid under a pressure of $100 \mathrm{MPa}$ through a nozzle with a special filter (for cutting the flow and additional homogenization) enters the various containers in a continuous stream. At the same time, inactivation of microbes occurs. Experimental data have shown that the overall efficiency of such an installation depends on the pressure in the working chamber.

Common semi-continuous systems for liquids high-pressure processing use compression chambers containing a free-piston for direct compression of food liquids. Which, after sealing, are suitable for sale. 
The batch method involves the use of small batches of food products for processing using high-pressure (periodic cycle). In this regard, there is an analogy with heat treatment: both processes are cyclical in that they fill the working vessel with a product, seal it, positioning the vessel into the high-pressure chamber. Then a compression-decompression cycle is carried out and product removal takes place. The working vessel can be in a vertical, horizontal and inclined position. The working chamber is usually under pressure above $400 \mathrm{MPa}$ and might be inbuilt in two or more concentric cylinders in a highly tensile stress state. External cylinders compress internal ones in the way that the walls of the highpressure chamber itself are under constant compression pressure, even during the creation of internal pressure. In order to create safe working conditions, the inner cylinder has the lowest strength characteristics. If the specified pressure limits values are exceeded, gaps occur in its walls and, as a result, the cylinder "leaks". In this case, the pressure decreases sharply, which helps to avoid explosive destruction of the entire working chamber. The outer cylinder of the working chamber can be equipped with a wire winding, or placed in a shirt constantly pressurized with liquid or a special cylinder. Typically, this entire system should withstand at least 10,000 loading and unloading cycles at a pressure of $680 \mathrm{MPa}$, or higher. The internal surfaces of the cooking chamber and all parts exposed to water and food components should be made of stainless steel to prevent corrosion. Parts of the system that consist of highly stretched tensile steel (non-stainless) may come in contact with foodsafe oils or water with appropriate lubricating additives (additives designated in foreign standards as FDA and USDA are compatible with food products) containing anti - corrosive components (subject to their sterility). The outer part of packages with products (if their processing in oil is necessary) can be covered with a sealed polymer film. In high-pressure processes (using a liquid food product), a chamber with an internal coating of stainless steel can come into contact directly with the food product, and the liquid medium (juices, food emulsions, etc.) in this case is the working fluid itself. Working chambers used in research practice usually have a volume ranging from 0.1 to 0.2 liters. In experimental enlarged installations, their capacity is 10 - 15 liters, while industrial batch chambers can have a capacity of up to several hundred liters. When using batch technology, the following operations are carried out: packaged products are placed in the chamber, the chamber is sealed and water is supplied into it until the air is completely displaced. When the chamber is full, the exhaust valve closes and the pump creates the necessary pressure. The compression rate is directly proportional to the power of the low pressure pump. After finishing the treatment process, the exhaust valve opens, allowing the water to expand until atmospheric pressure is reached. Then the working chamber opens and the packaged products are removed. Air removal (both from the working chamber and from the food product) is performed before the compression stage to reduce the cost of creating pressure. The volume of residual air is so small that it does not affect the effectiveness of high pressure on the microbial environment in the food product. In this regard, the amount of residual air in the working system is not a critical factor. $100 \mathrm{hp}$ pump (horsepower) is able to create a pressure of $680 \mathrm{MPa}$ in a 50 liter vessel in 3 to 4 minutes period. In this regard, as it has already been mentioned, compression time is a function of pump power. During normal operation, the pressure of the transmission medium (usually water) should be above $200 \mathrm{MPa}$. The estimated water volumes [19], which are necessary for substances pumping into a definite capacity vessel in order to achieve the required pressure, are given in the literature, but they (these data) do not take into account changes in the volume of the vessel itself and the associated communications. This change may amount to several percent. From practical data it is known that to create a pressure of $680 \mathrm{MPa}$ in a vessel with a capacity of $100 \mathrm{l}$, an additional injection of 15 liters is necessary [19]. The high cost of the high-pressure chamber, pump, compression amplifier, and system seals dictates the creation 
of conditions for increasing the frequency of cyclic food processing operations at given pressures [20,21].

In this regard, the goal of our research is to study ultra-high pressure on the perishable food products shelf life, using chilled meat raw materials as an example, and to develop a device for processing food products with ultra-high pressure.

\section{Materials and Methods}

For the research, two groups of samples of chilled beef were formed (control and experimental), 5 samples in each with a weight of $300 \mathrm{~g}$ were packed in a vacuum package. The meat samples of the control group were not pressure-treated; the meat samples of the experimental group were treated with a pressure of $800 \mathrm{MPa}$ for 6 minutes. Then the meat was stored at $4^{\circ} \mathrm{C}$ for 60 days.

To determine the meat preservation, organoleptic indicators, protein content according to Keldahl, fat were determined by the Soxhlet method, microbiological indicators were determined according to GOST R 54354-2011 Requirements, the acid number of fat was determined according to GOST R 55480-2013, and the peroxide value was determined according to GOST R 51487-99. The studies were carried out in 5-fold repetition and the results were processed using the Statistica-9 computer program.

\section{Results and Discussion}

As a result of the studies, it was found that the meat samples of the control group after 60 days of storage did not meet the requirements of the Technical Regulation of the Customs Union TR CU 034/2013 "On the safety of meat and meat products" by microbiological indicators. So, KMAFAnM indicator was at the level of $3.4 \times 105 \mathrm{CFU} / \mathrm{g}$, yeast was at the $5.1 \times 105$ level, while in the meat samples of the experimental group the studied parameters corresponded to the norm (KMAFAnM no more than $1.0 \cdot 104 \mathrm{CFU} / \mathrm{g}$, yeast no more 1 . $103 \mathrm{CFU} / \mathrm{g}$.). The results are consistent with organoleptic indicators. The meat samples of the control group had a strongly dried out and in some places greyed-brown mucus appearance, sour smell, the muscles on the cut were moist and left a wet spot on the filter paper, differed in a loose texture and the pit did not even out when pressed with a finger, while the meat samples of the experimental group corresponded to fresh - they had a pale red color, a drying crust, the muscles in the section were slightly moist with an elastic consistency, when pressed with a finger, the fossa quickly leveled off.

Figure 1 shows meat samples acid number dynamic.

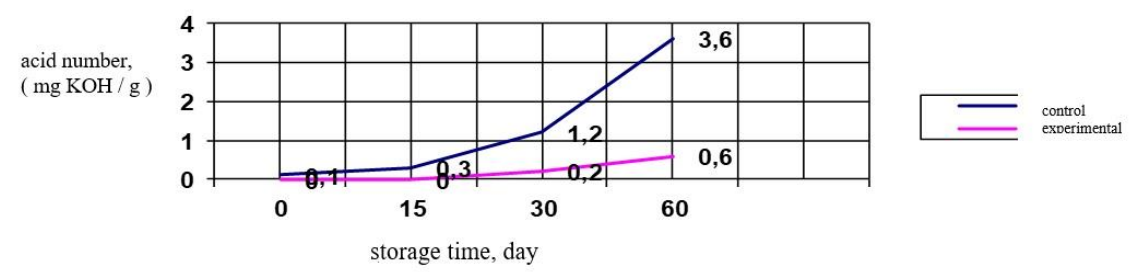

Fig 1. Control and experimental meat samples ( $\mathrm{mg} \mathrm{KOH} / \mathrm{g}$ ) acid number dynamics

From figure 1 it follows that in the samples of meat of the control group after 30 and 60 days of storage, the acid number is at the level of 1.2 and $3.6 \mathrm{mg} \mathrm{KOH}$, while in the experimental 0.2 and $0.6 \mathrm{mg} \mathrm{KOH}$. 
Similar results were obtained in the study of peroxide value (Figure 2).

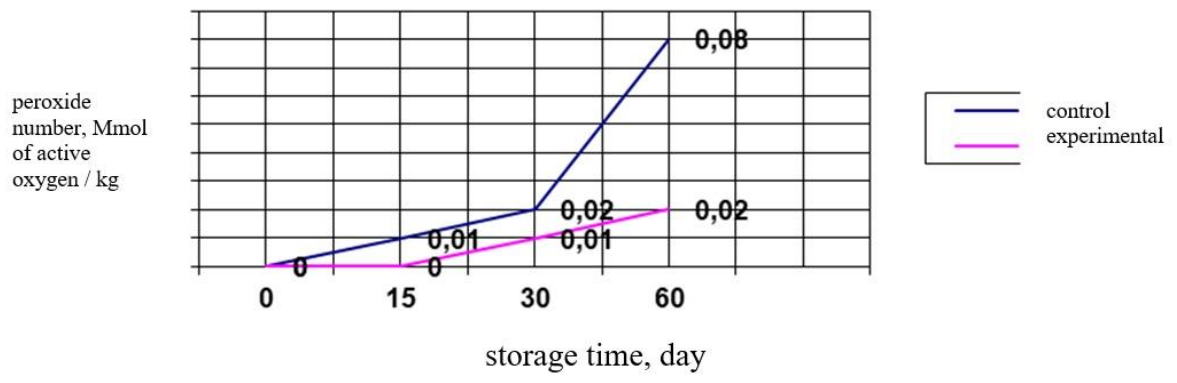

Fig 2. Dynamics of the peroxide number of control and experimental meat samples, Mmol of active oxygen / kg

The research results are consistent with the organoleptic assessment of meat during storage.

When studying the chemical composition of meat, it was found that in the control samples of meat after 60 days of storage, there was a slight decrease in protein content from 19.3 (background) to $18.7 \%$ (60 days of storage), while in the experimental ones the amount of protein was at 19.4 and $19.1 \%$, respectively. There was a decrease in the amount of fat during storage in the control group by $4.3 \%$, in the experimental group it was by $1.7 \%$.

The results are explained by the destruction of multi-ether bonds in triglycerides with the participation of water, which is accompanied by the accumulation of free fatty acids. This process is catalyzed by both tissue lipases and lipolytic enzymes of microorganisms, which retain their viability in raw materials not treated with high pressure.

The calculations of equipment (hydraulic cylinder) for processing meat and meat products with ultrahigh pressure have been carried out. Figure 3 shows a diagram of the hydraulic cylinder.

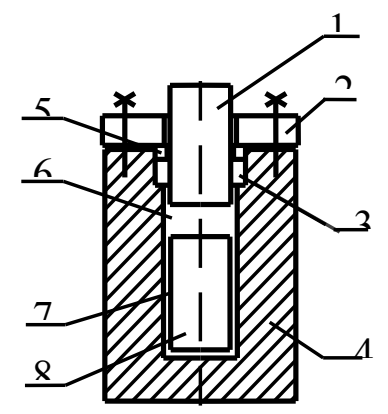

Fig. 3. Diagram of a device for processing meat and meat with liquid in a comprehensive compression:

1 - punch; 2 - flange; 3 - seal; 4 - a working chamber; 5 - washer; 6 - working fluid; 7 shell; 8 - object of study (product)

Design pressure according to the strength condition Rpr1, MPa:

Pprl = P1max - Ratm,

where P1max is the maximum overpressure inside the hydrostatic cylinder, MPa; Ratm - atmospheric pressure, MPa.

For the calculation we take $\mathrm{P} 1 \mathrm{max}=1200 \mathrm{MPa}$; Ratm $=0.1 \mathrm{MPa}$.

Then the calculated pressure under the condition of strength will be:

Ppr1 $=1,200-0.1=1,199.9 \approx 1,200 \mathrm{MPa}$. 
Since pressures are less than atmospheric in the hydrostatic cylinder, it is not assumed that the chamber is calculated only according to the strength conditions.

We calculate the wall thickness of the hydraulic cylinder according to the theory of strength. The cylinder is made of autofretched high-strength steel grade O-AB.

Design wall thickness of the hydraulic cylinder of the compression chamber S1, mm:

$\mathrm{S} 1=\mathrm{Sp} 1-\mathrm{C} 1$,

where $\mathrm{Sp} 1$ is the estimated wall thickness of the hydraulic cylinder, mm; C1 - an increase to the calculated thickness, taking into account the process of corrosion of the material, $\mathrm{mm}$, which is calculated by the formula:

$\mathrm{C} 1=\mathrm{A}-\mathrm{t}$,

where $\mathrm{A}$ is the estimated corrosion rate of the material of construction, $\mathrm{mm} /$ year; $\mathrm{t}$ is the planned life of the hydrostat, year.

For calculation, we take $\mathrm{t}=10$ years, $\mathrm{A}=0.005 \mathrm{~mm} /$ year according to the standard for vessels and apparatus under pressure.

$\mathrm{C} 1=0.005-10=0.05 \mathrm{~mm} /$ year.

The estimated wall thickness of the hydraulic cylinder of the compression chamber Sp1, $\mathrm{mm}$ :

$\mathrm{Sp} 1=\max \{\mathrm{Sn} 1 ; \mathrm{Sy} 1\}$,

The largest of the obtained values is selected (as the calculated wall thickness of the hydraulic cylinder) according to the conditions of strength Sn1, mm, and stability Sy1, mm. Sn1.

Since the calculation according to the stability conditions is not performed, then $\mathrm{Sp} 1=$

The estimated radius of the hydraulic cylinder of the compression chamber according to the strength conditions $\mathrm{Rk}$ is, $\mathrm{cm}$ :

$$
R_{\mathrm{K}}=R_{0} \sqrt{\frac{\sigma_{\mathrm{p}}+0,4 \mathrm{P}_{y}}{\sigma_{\mathrm{p}}-1,3 \mathrm{P}_{y}}},
$$

where R0 is the inner radius of the cylinder body, sufficient to accommodate food samples and semi-finished products in it, we take $\mathrm{R} 0=100 \mathrm{~mm}$; $\sigma \mathrm{p}$ - permissible tensile stress of the body material, for autofrequered high-strength steel O-AB $\sigma p \geq 50 \mathrm{MPa}$; Py design pressure of the working fluid $(\mathrm{Py}=1.2 \mathrm{Pmax})$;

$$
\begin{gathered}
\mathrm{P}_{y}=1,2 \cdot 1200=1440 \text { МПа. } \\
R_{\mathrm{K}}=10 \sqrt{\frac{5000+0,4 \cdot 1440}{5000-1,3 \cdot 1440}}=13,35=14 \mathrm{~cm} .
\end{gathered}
$$

The estimated wall thickness of the hydraulic cylinder $\mathrm{Sn} 1$ is, $\mathrm{cm}$ :

$$
S_{n 1}=R_{\mathrm{K}}-R_{0} \text {. }
$$

Design wall thickness of the hydraulic cylinder of the compression chamber $\mathrm{S} 1$ is, $\mathrm{mm}$ :

$$
S_{1}=40+0,05=40,5 \mathrm{MM} \text {. }
$$

We have rounded the resulting value to $\mathrm{S} 1=42 \mathrm{~mm}$.

\section{Conclusion}

As a result of the chilled meat ultra-high pressure effect on the chilled meat shelf life during refrigerated storage, it was found that 6 minutes meat processing at $800 \mathrm{MPa}$ provides high organoleptic characteristics (color, smell, texture) stability, microbiological safety, so KMAFAnM, yeast and other studied parameters do not exceed the technical regulation requirements of the Customs Union "On Food Safety" (TR TS 021/2011), prevents protein breakdown, and promotes oxidative damage. At that time, samples of chilled meat not processed by pressure after 60 days of refrigerated storage according to 
organoleptic, physicochemical and microbiological indicators were considered to be stale. Therefore, the processing of meat, packed in vacuum packaging, helps to increase its storage time. We have calculated the design of equipment for processing meat with high pressure, by comprehensive compression of the working fluid in a special working chamber

\section{References}

1. C.E. Leadley, A. Williams, New Technologies Bull., 14, 35 (1997)

2. L.S. Kudryashov, S.L. Tikhonov, N.V. Tikhonova, V.M. Poznyakovsky, N.Yu. Stozhko, O.A. Kudryashova, Hygiene and sanitation, 97 (3), 259 (2018)

3. L.S. Kudryashov, A.B. Lisitsin, S.L. Tikhonov, N.V. Tikhonova, A.Yu. Volkov, A.V. Aleksandrov, Meat industry, 2, 37 (2016)

4. J.C. Cheftel, Food Sci., Technol. Int., 1, 75 (1995)

5. K. Autio, Espoo., 199 (1998)

6. K. Heremans, Effects of high pressure on biomaterials, In: Ultra High Pressure Treatments of Foods, Hendrickx, M.E.G., D. Knorr, New York: Kluwer Academic Plenum Publishers, 23 (2002)

7. J.A. Torres, G. Velazquez, J. of Food Engineering, 67, 95 (2005)

8. A.V. Bannikova, I.A. Evdokimov, Dairy industry, 11, 100102 (2014)

9. P. George, A. Bannikova, N. Mantri, S. Kasapis, M. Palmer, B. Meurer, Food Hydrocolloids, 32, 286 (2013)

10. S. Savadkoohi, A. Bannikova, S. Kasapis, B. Adhikari, Food Chemistry, 150, 469 (2014)

11. A.V. Bannikova, I.A. Evdokimov. An innovative approach to creating enriched dairy products with a high protein content, 136 (M .: DeLi Plus, 2015)

12. B.R. Thacur, P.E. Nelson, Food Reviews Int., 14, 427 (1998)

13. D. Knorr, Advantages and limitations of non - thermal food preservation methods, VTT Symp. New Shelf - Life Technologies and Safety Assessments (Technical Research Center of Finland), 7 (1995)

14. D. Far, Trends Food Sci. Technol., 1, 14 (1990)

15. I. Kloczko, M. Radomski, Phzemysl Spozywczy, 50, 25 (1996)

16. B.K. Touscher, Effect of high pressure treatment to nutritive subctances and natural pigments, Fresh Novel Foods by High Pressure (VTT Symposium, Technical Research Center of Finland. Helsinki, Finland) 198, 186 (1997)

17. G. Jahn, Molkerei - Zeitung Welt der Milch, 50 (23), 916 (1996)

18. J.E. Moorman, R.T. Toledo. K. Schmidt, High - pressure throttling (HPT) reduced microbial population? Improves yigurt consistency and modifies rheological properties of ultrafiltered milk, IFT Annual Meeting: Book of Abstracts, 49 (1996)

19. H.D. Ludemann, Water and aqueous solution under high pressure, High pressure and Biotechnology, 224(London. Colloquia INSERM, John Libbey Euritext LTD, 1992)

20. G.D. Aleman, E.Y. Ting, S.C. Mordre, J. Food Sci., 61 (2), 388 (1996)

21. K.D. Joshi, G. Jyoti, C. Satishi, J. of Food Safety, 12, 59 (1991) 